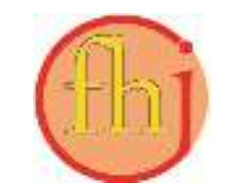

Faletehan Health Journal, 8 (1) (2021) 58-64

www. journal.Ippm-stikesfa.ac.id/ojs/index.php/FHJ

ISSN 2088-673X | e-ISSN 2597-8667

\title{
Gambaran Usia, Paritas, Tingkat Pendidikan, Status Pekerjaan, Dukungan Suami dan Tingkat Pengetahuan Ibu dalam Pemberian ASI Eksklusif
}

\author{
Feling Polwandari ${ }^{1 *}$, Sonia Wulandari ${ }^{1}$ \\ ${ }^{1}$ Universitas Faletehan \\ *Corresponding Author: greenfeling21@gmail.com
}

\begin{abstract}
Abstrak
ASI eksklusif adalah pemberian ASI tanpa makanan tambahan lain pada bayi berumur 0-6 bulan. Berbagai penelitian membuktikan bahwa pemberian ASI Eksklusif dapat meningkatkan kekebalan dan kecerdasan anak. Oleh karena itu, pemerintah melalui Keputusan Menteri Kesehatan No. 450/MENKES/SK/VI/2004 menganjurkan pemberian ASI secara Eksklusif. Akan tetapi, anjuran tersebut belum dilakukan oleh semua ibu menyusui. Penelitian ini bertujuan untuk mengetahui gambaran usia, paritas, tingkat pendidikan, status pekerjaan, dukungan suami dan tingkat pengetahuan ibu dalam pemberian ASI eksklusif. Desain Penelitian ini adalah deskriptif dengan studi kasus dengan pengambilan sampel di Desa Pelamunan yang berjumlah 54 responden ibu yang mempunyai bayi usia 0-6 bulan. Pengumpulan data dilakukan dengan menggunakan kuesioner yang berisikan karakteristik dan pengetahuan ibu tentang ASI eksklusif. Hasil penelitian menunjukkan sebagian besar usia ibu menyusui tidak beresiko sebesar $84 \%$, paritas multipara atau grandemultipara $77,5 \%$, pendidikan rendah $83 \%$, tidak bekerja $77 \%$, suami yang sangat mendukung $81 \%$, dan sebagian besar ibu menyusui berpengetahuan baik $79 \%$. Petugas kesehatan diharapkan dapat memberikan penyuluhan pemberian ASI eksklusif kepada semua kalangan masyarakat, dan bagi peneliti lain untuk dapat melakukan penelitian mengenai mengatasi hambatan proses menyusui dengan metode yang lebih baik dari deskriptif.
\end{abstract}

Kata Kunci: ASI Eksklusif, Karakteristik Ibu, Pengetahuan Ibu

\section{The Depiction of Age, Parity, Education Level, Employment Status, Husband Support, and Maternal Knowledge Level in Exclusive Breastfeeding}

\begin{abstract}
Exclusive breastfeeding is breastfeeding without any additional food for infants aged 0-6 months. Various studies showed that exclusive breastfeeding improves children's immunity and intelligence. Based on this fact, The Government gave recommendation through Health Minister Decision No. 450/MENKES/SK/VI/2004 about exclusive breastfeeding. However, not all mothers followed this recommendation. This study was conducted to determine the description of age, parity, education level, employment status, husband support, and maternal knowledge level in exclusive breastfeeding. This research is a descriptive study with case study by taking samples from Pelamunan Village as many as 54 respondents who have babies aged 0-6 months. The data collection was carried out by using a questionnaire of maternal characteristics and knowledge about exclusive breastfeeding. The results showed the majority of breastfeeding mothers are not at risk (84\%), multiparity or grand multipara $(77.5 \%)$, low education (83\%), not working (77\%), very supportive husbands (81\%), and most breastfeeding mothers are knowledgeable (79\%). Health officers were expected to do exclusive breastfeeding promotion to people of all circles and other researchers to answer the obstacles in the breastfeeding process by a better research method than descriptive.

Keywords: Exclusive Breastfeeding, Maternal Characteristics, Maternal Knowledge
\end{abstract}


Faletehan Health Journal, 8 (1) (2021) 58-64

\section{Pendahuluan}

Air Susu Ibu (ASI) adalah cairan yang diproduksi dari payudara ibu dan menjadi makanan terbaik yang paling sempurna untuk bayi. Jenis ASI dibagi menjadi 3 yaitu kolostrum, ASI peralihan dan ASI matur sehingga kandungan gizi yang tinggi dan adanya zat kebal didalamnya membuat ASI tidak tergantikan oleh susu formula yang paling hebat dan mahal sekalipun (Yusrina \& Devy, 2017). Proses pemberian ASI tanpa makanan tambahan lain pada bayi berumur 0-6 bulan disebut ASI eksklusif. ASI eksklusif yang dimaksud yaitu bayi tidak diberikan apapun, kecuali makanan yang langsung diproduksi oleh ibu yaitu ASI (Kemenkes, 2018). Pemberian ASI eksklusif di Negara berkembang berhasil menyelamatkan sekitar 1,5 juta bayi/tahun. Atas dasar tersebut World Health Organization (WHO) merekomendasikan untuk hanya memberikan ASI eksklusif sampai bayi berusia 6 bulan (WHO, 2015).

Data tren menunjukkan prevalensi ASI eksklusif pada bayi di bawah enam bulan di negara berkembang meningkat dari 33\% pada tahun 1995 menjadi 39\% pada tahun 2010. Prevalensinya meningkat di hampir semua wilayah di dunia berkembang, dengan peningkatan terbesar terlihat di Afrika Barat dan Tengah (Cai et al., 2012). Proporsi pola pemberian ASI 0-5 bulan di Indonesia pada tahun 2018 adalah 37, $3 \%$ (Kemenkes RI, 2018). Persentase pemberian ASI eksklusif pada bayi 0-6 bulan di Provinsi Banten pada tahun 2017 menurun menjadi 50,8 \% dan cakupan ASI eksklusif di Kabupaten Serang yaitu 60,06 \% (Dinkes Provinsi Banten, 2018). Data ibu menyusui di Desa Pelamunan tahun 2018 diperoleh 306 ibu menyusui, yang memberikan ASI eksklusif sebanyak 219 dan yang tidak memberikan ASI eksklusif sebanyak 87. Jika dipersentasekan ibu yang memberikan ASI eksklusif di Desa Pelamunan tahun 2018 hanya sebesar 71,57\% (UPT Puskesmas Kramatwatu, 2018).

Keputusan Menteri Kesehatan No. 450/MENKES/SK/VI/2004 menganjurkan pemberian ASI secara Eksklusif selama 6 bulan lalu berlanjut sampai anak berusia 2 tahun atau lebih dengan pemberian makanan tambahan, namun himbauan tersebut belum dilakukan oleh semua ibu yang menyusui bila dilihat dari cakupan ASI eksklusif yang dijabarkan pada paragraf sebelumnya (Kemenkes RI, 2004). Rendahnya cakupan ASI dipengaruhi oleh beberapa faktor, antara lain usia ibu, tingkat pendidikan, status pekerjaan, urutan kelahiran bayi, pengetahuan ibu, dukungan suami atau keluarga (Puspitasari, 2012). Informasi yang tidak tepat menjadi salah satu sebab mengapa masih terdapatnya ibu yang tidak memberikan ASI eksklusif dikarenakan ibu tidak mengetahui bagaimana cara menyusui yang baik supaya produksi ASI melimpah dan hambatanhambatan lainnya (Febriyanti, Rosalina \& Ernawati, 2017). Dampak ibu yang tidak memberikan ASI Eksklusif pada bayi dibawah 6 bulan akan menyebabkan risiko bayi terkena berbagai penyakit seperti infeksi saluran pernapasan, infeksi telinga, daya imunitas rendah, berakibat pada generasi penerus bangsa yang kurang cerdas, meningkatkan angka kesakitan, meningkatkan kematian anak, menambah subsidi rumah sakit dan menambah devisa untuk membeli susu formula (Nugroho, 2011).

Oleh karena itu peneliti sekiranya perlu melakukan penelitian terkait gambaran usia, paritas, pendidikan, pekerjaan, dukungan suami dan pengetahuan responden dalam pemberian ASI.

\section{Metodologi Penelitian}

Penelitian ini merupakan penelitian deskriptif studi kasus dengan tujuan penelitian untuk mengetahui gambaran usia, paritas, tingkat pendidikan, status pekerjaan, dukungan suami dan tingkat pengetahuan ibu dalam pemberian ASI eksklusif di Desa Pelamunan Wilayah Kerja UPT Puskesmas Kramatwatu Kabupaten Serang Provinsi Banten tahun 2019.

Populasi penelitian ini adalah seluruh ibu yang memiliki bayi usia 0-6 bulan di Desa Pelamunan yang melakukan kunjungan nifas di UPT Puskesmas Kramatwatu Kabupaten Serang Provinsi Banten pada periode Bulan November 2018 - Maret 2019 sebanyak orang 116 orang. Kriteria inklusi sampel adalah ibu yang memiliki bayi usia 0-6 bulan bersedia menjadi responden, dapat membaca dan menulis dan memiliki suami. Kriteria drop out sampel adalah bila responden tidak menjawab seluruh soal dan bercerai dengan suami saat proses penelitian berlangsung. Teknik pengambilan sampel dalam penelitian ini adalah simple random sampling dan didapatkan sample sebanyak 54 ibu nifas dengan menggunakan rumus Slovin. 
Penelitian ini menggunakan data primer yaitu kuesioner yang berisi tentang pertanyaanpertanyaan mengenai karakteristik (usia, paritas, pendidikan, pekerjaan, dukungan suami) dan pengetahuan tentang ASI eksklusif. Kuesioner dukungan suami menggunakan kuesioner peneliti sebelumya dan sudah dilakukan uji validitas diperoleh 25 pertanyaan valid dengan $r$ hitung $>$ 0,396 ( $\mathrm{r}$ tabel) dan uji reliabilitas (Cronbach's Alpha) menunjukan nilai $\mathrm{r}$ alpha $(0,967)$ (Hargi, 2013). Kuesioner pengetahuan ibu terdiri dari 31 pertanyaan namun tidak dilakukan uji validitas dan reliabilitas karena pertanyaan diambil dari teori tentang ASI eksklusif yang sudah ada. Data sekunder diperoleh dari rekam medik yang berada di UPT Puskesmas Kramatwatu yaitu data ibu yang mempunyai bayi berusia $0-6$ bulan yang melakukan kunjungan nifas pada periode bulan November 2018 sampai Maret 2019.

\section{Hasil dan Pembahasan}

\section{Gambaran Pemberian ASI Eksklusif berdasarkan Usia Ibu}

Tabel 1. Distribusi Frekuensi Pemberian ASI Eksklusif berdasarkan Usia Ibu Di Desa Pelamunan Wilayah Kerja UPT Puskesmas Kramatwatu Kabupaten Serang Provinsi Banten Tahun 2019

\begin{tabular}{|c|c|c|c|c|c|c|}
\hline \multirow{3}{*}{ Usia } & \multicolumn{4}{|c|}{$\begin{array}{c}\text { Pemberian ASI } \\
\text { Eksklusif }\end{array}$} & \multirow{3}{*}{$\mathbf{n}$} & \multirow{3}{*}{$\%$} \\
\hline & \multicolumn{2}{|c|}{ Ya } & \multicolumn{2}{|c|}{ Tidak } & & \\
\hline & $\mathbf{F}$ & $\%$ & $\mathbf{F}$ & $\%$ & & \\
\hline Beresiko & 5 & 50 & 5 & 50 & 10 & 100 \\
\hline Tidak Beresiko & 37 & 84 & 7 & 16 & 44 & 100 \\
\hline Jumlah & 42 & & 12 & & 54 & \\
\hline
\end{tabular}

Sumber: Data Primer Periode April 2019

Tabel 1 diperoleh hasil bahwa dari 54 responden, mayoritas ibu yang memberikan ASI Eksklusif adalah usia ibu yang tidak berisiko (2035 tahun) yaitu sebanyak 37 orang (84\%). Responden di rentang usia 20-35 tahun adalah masa dewasa dimana pada usia ini ibu dapat memecahkan masalah dengan baik yang salah satunya akan mencari informasi akurat terkait pemberian ASI Eksklusif. Ibu berusia <20 tahun dianggap masa belum matang baik secara rohani dan jasmani sehingga ibu akan mengandalkan orang lain dalam memberikan ASI Eksklusif. Ibu dengan usia $>35$ tahun mulai mengalami perubahan pada sistem hormonalnya sehingga produksi ASI yang dihasilkan berkurang dan akan menjadi hambatan untuk ibu dalam memberikan ASI secara eksklusif (Afriyani et al., 2018).

Ibu yang memberikan ASI eksklusif di Desa Pelamunan Wilayah Kerja UPT Puskesmas Kramatwatu sebagian besarnya adalah ibu yang berusia 20-35 tahun dan hal ini sejalan dengan teori penelitian sebelumnya yaitu adanya hubungan usia ibu dengan pemberian ASI eksklusif dimana ibu rentang usia 20-35 tahun lebih banyak memberikan ASI eksklusif kepada anaknya, didapatkan $\mathrm{p}$ value $=0,025$ dengan nilai $\mathrm{OR}=2,967$ (Khoiriah, 2018). Dapat disimpulkan penelitian ini sejalan dengan teori sebelumnya bahwa rentang usia 20-35 tahun adalah usia matang dimana seorang ibu menyusui semakin cukup umur, maka memiliki tingkat pemikiran yang matang dalam mencari informasi dan merawat bayinya khususnya dalam pemberian ASI Eksklusif.

\section{Gambaran Pemberian ASI Eksklusif berdasarkan Paritas}

Tabel 2. Distribusi Frekuensi Pemberian ASI Eksklusif berdasarkan Paritas Di Desa Pelamunan Wilayah Kerja UPT Puskesmas Kramatwatu Kabupaten Serang Provinsi Banten Tahun 2019

\begin{tabular}{|c|c|c|c|c|c|c|}
\hline \multirow{3}{*}{ Paritas } & \multicolumn{4}{|c|}{$\begin{array}{c}\text { Pemberian ASI } \\
\text { Eksklusif }\end{array}$} & \multirow{3}{*}{$\mathbf{n}$} & \multirow{3}{*}{$\%$} \\
\hline & \multicolumn{2}{|c|}{ Ya } & \multicolumn{2}{|c|}{ Tidak } & & \\
\hline & $\mathbf{F}$ & $\%$ & $\mathbf{F}$ & $\%$ & & \\
\hline Primipara & 11 & 79 & 3 & 21 & 14 & 100 \\
\hline $\begin{array}{l}\text { Multipara/ } \\
\text { Grande } \\
\text { Multipara }\end{array}$ & 31 & 77,5 & 9 & 22,5 & 40 & 100 \\
\hline Jumlah & 42 & & 12 & & 54 & \\
\hline
\end{tabular}

Sumber: Data Primer Periode April 2019

Tabel 2 diperoleh hasil bahwa dari 54 responden, mayoritas ibu yang memberikan ASI Eksklusif adalah ibu multipara atau grande multipara dengan jumlah 31 orang (77,5\%). Paritas adalah wanita yang pernah melahirkan. Paritas dibagi menjadi beberapa istilah yaitu primipara yaitu seseorang wanita yang pernah melahirkan janin untuk pertama kali, multipara yaitu seseorang wanita yang telah melahirkan janin lebih dari satu kali, dan grande multipara yaitu seseorang wanita yang telah melahirkan janin lebih dari lima kali (Manuaba, 2013).

Penelitian sebelumnya menjelaskan adanya hubungan antara paritas dan pemberian ASI eksklusif $(\mathrm{p}=0,006)$ dan hasil uji regresi logistik Wald $=4,602(\mathrm{p}=0,032)$ yang dapat diartikan ibu 
Faletehan Health Journal, 8 (1) (2021) 58-64

multipara atau grande multipara berpeluang memberikan ASI Esklusif sebesar 4,60 kali dibandingkan dengan ibu primipara. Paritas dikaitkan dengan pengalaman ibu saat menyusui. Ibu dengan paritas lebih dari satu akan lebih percaya diri dan mampu mengatasi hambatanhambatan yang terjadi selama proses menyusui (sebagai contohnya adalah cara mengatasi ASI tidak keluar) sehingga ibu multipara atau grande multipara lebih berpeluang untuk memberikan ASI secara eksklusif (Gobel et al., 2012). Hasil penelitian ini sejalan dengan penelitian sebelumnya dimana sebagian besar ibu multipara atau grande multipara di Desa Pelamunan Wilayah Kerja UPT Puskesmas Kramatwatu memberikan ASI eksklusif.

\section{Gambaran Pemberian ASI Eksklusif berdasarkan Tingkat Pendidikan Ibu}

Tabel 3. Distribusi Frekuensi Pemberian ASI Eksklusif berdasarkan Tingkat Pendidikan Di Desa Pelamunan Wilayah Kerja UPT Puskesmas Kramatwatu Kabupaten Serang Provinsi Banten Tahun 2019

\begin{tabular}{|c|c|c|c|c|c|c|}
\hline \multirow{3}{*}{ Pendidikan } & \multicolumn{4}{|c|}{$\begin{array}{c}\text { Pemberian ASI } \\
\text { Eksklusif }\end{array}$} & \multirow{3}{*}{$\mathbf{n}$} & \multirow{3}{*}{$\%$} \\
\hline & \multicolumn{2}{|c|}{ Ya } & \multicolumn{2}{|c|}{ Tidak } & & \\
\hline & $\mathbf{F}$ & $\%$ & $\mathbf{F}$ & $\%$ & & \\
\hline Rendah & 19 & 17 & 4 & 83 & 23 & 100 \\
\hline Menengah & 11 & 73 & 5 & 27 & 16 & 100 \\
\hline Tinggi & 12 & 80 & 3 & 20 & 15 & 100 \\
\hline Jumlah & 42 & & 12 & & 44 & \\
\hline
\end{tabular}

Sumber: Data Primer Periode April 2019

Tabel 3 diperoleh hasil bahwa dari 54 responden, mayoritas ibu yang memberikan ASI Eksklusif adalah yang pendidikannya rendah dengan jumlah 19 orang (83\%). Penelitian sebelumnya menjelaskan bahwa ibu yang memiliki pendidikan tinggi mampu menerima informasi mengenai pemberian ASI Eksklusif dengan baik dan memiliki pengetahuan yang lebih luas tentang ASI Eksklusif dibandingkan dengan responden yang berpendidikan rendah (Afriyani et al., 2018).

Penelitian lain juga menjelaskan pendidikan tidak mempengaruhi dalam pemberian ASI eksklusif karena ada hal lain yang dapat mempengaruhi pemberian ASI eksklusif seperti kepercayaan dan kebudayaan masyarakat yang ada disekitarnya ( $\mathrm{p}=0,009)$, sehingga informasi yang didapat terkait ASI eksklusif tidak dapat dipraktikan dengan baik oleh para ibu menyusui (Asare et al., 2018).

Hasil penelitian Asare dan kawan-kawan sejalan dengan hasil penelitian di Desa Pelamunan Wilayah Kerja UPT Puskesmas Kramatwat dimana ibu yang memberikan ASI eksklusif adalah tidak selalu ibu dengan tingkat pendidikan yang tinggi tetapi ibu dengan tingkat pendidikan rendah lebih dapat mengaplikasikan ASI eksklusif dikarenakan faktor-faktor lain yang mendukungnya salah satunya adalah faktor budaya masyarakat setempat.

\section{Gambaran Pemberian ASI Eksklusif berdasarkan Status Pekerjaan Ibu}

Tabel 4. Distribusi Frekuensi Pemberian ASI Eksklusif berdasarkan Status Pekerjaan Ibu Di Desa Pelamunan Wilayah Kerja UPT Puskesmas Kramatwatu Kabupaten Serang Provinsi Banten Tahun 2019

\begin{tabular}{|c|c|c|c|c|c|c|}
\hline \multirow{3}{*}{ Pekerjaan } & \multicolumn{4}{|c|}{$\begin{array}{c}\text { Pemberian ASI } \\
\text { Eksklusif }\end{array}$} & \multirow{3}{*}{$\mathbf{n}$} & \multirow{3}{*}{$\%$} \\
\hline & \multicolumn{2}{|c|}{ Ya } & \multicolumn{2}{|c|}{ Tidak } & & \\
\hline & $\mathbf{F}$ & $\%$ & $\mathbf{F}$ & $\%$ & & \\
\hline Bekerja & 8 & 80 & 2 & 30 & 10 & 100 \\
\hline $\begin{array}{l}\text { Tidak } \\
\text { Bekerja }\end{array}$ & 34 & 77 & 10 & 23 & 44 & 100 \\
\hline Jumlah & 42 & & 12 & & 54 & \\
\hline
\end{tabular}

Sumber: Data Primer Periode April 2019

Tabel 4 diperoleh hasil bahwa dari 54 responden, mayoritas ibu yang memberikan ASI Eksklusif adalah ibu yang tidak bekerja yaitu berjumlah 34 orang (77\%). Pekerjaan bukan alasan untuk mengehentikan pemberian ASI Eksklusif. Terdapat penelitian yang menjelaskan adanya hubungan antara status pekerjaan dengan pemberian ASI Eksklusif dimana ibu yang bekerja memiliki kecenderungan tidak memberikan ASI Eksklusif. Pengetahuan yang benar tentang menyusui, perlengkapan memerah ASI dan dukungan lingkungan kerja, seorang ibu dapat tetap memberikan ASI secara Eksklusif. Adanya tuntutan dan kesempatan bekerja untuk membantu ekonomi keluarga, sebagian ibu-ibu memilih bekerja di luar rumah. Oleh karena itu, dengan bekerja para ibu tidak dapat berhubungan penuh dengan bayinya, akibatnya ibu lebih cenderung memberikan susu formula yang menyebabkan frekuensi menyusui akan berkurang dan produktivitas ASI akan menurun. Keadaan inilah yang menyebabkan ibu berhenti memberikan ASI, 
sedangkan ibu yang tidak bekerja memiliki waktu luang dan dapat melakukan kontak langsung dengan bayi saat menyusui, sehingga produktivitas ASI menjadi banyak (Widdefrita \& Mohanis, 2014). Penelitian lain juga menjelaskan kemungkinan ibu yang bekerja relatif dibebani dengan aktivitas kantor dan rumah sehingga ibu tidak memiliki waktu yang cukup untuk kontak langsung dengan bayinya (Asemahagn, 2016).

Hasil penelitian yang ada sejalan dengan penelitian yang dilakukan di Desa Pelamunan Wilayah Kerja UPT Puskesmas Kramatwatu, yaitu ibu yang memberikan ASI eksklusif sebagian besarnya adalah ibu yang tidak bekerja dimana ibu yang tidak bekerja banyak memiliki waktu luang sehingga dapat leluasa kontak langsung dalam proses menyusui dan memberika ASI eksklusif.

\section{Gambaran Pemberian ASI Eksklusif berdasarkan Dukungan Suami Ibu}

Tabel 5. Distribusi Frekuensi ASI Eksklusif berdasarkan Dukungan Suami Ibu Di Desa Pelamunan Wilayah Kerja UPT Puskesmas Kramatwatu Kabupaten Serang Provinsi Banten Tahun 2019

\begin{tabular}{|c|c|c|c|c|c|c|}
\hline \multirow{3}{*}{$\begin{array}{c}\text { Dukungan } \\
\text { Suami }\end{array}$} & \multicolumn{4}{|c|}{$\begin{array}{c}\text { Pemberian ASI } \\
\text { Eksklusif }\end{array}$} & \multirow{3}{*}{$\mathrm{n}$} & \multirow{3}{*}{$\%$} \\
\hline & \multicolumn{2}{|c|}{ Ya } & \multicolumn{2}{|c|}{ Tidak } & & \\
\hline & $\mathbf{F}$ & $\%$ & $\mathbf{F}$ & $\%$ & & \\
\hline $\begin{array}{l}\text { Tidak } \\
\text { Mendukung }\end{array}$ & 2 & 67 & 1 & 33 & 3 & 100 \\
\hline $\begin{array}{l}\text { Kurang } \\
\text { Mendukung }\end{array}$ & 5 & 83 & 3 & 17 & 8 & 100 \\
\hline $\begin{array}{l}\text { Sangat } \\
\text { Mendukung }\end{array}$ & 35 & 81 & 8 & 19 & 43 & 100 \\
\hline Jumlah & 42 & & 12 & & 54 & \\
\hline
\end{tabular}

Sumber: Data Primer Periode April 2019

Tabel 5 diperoleh hasil bahwa dari 54 responden, mayoritas ibu yang memberikan ASI Eksklusif adalah ibu yang suaminya sangat mendukung dalam pemberian ASI Eksklusif yaitu sebanyak 35 orang $(81 \%)$. Dukungan suami merupakan salah satu faktor yang mempengaruhi keberhasilan dalam pemberian ASI Eksklusif. Cara terbaik yang dapat dilakukan suami dalam memberi dukungan pada ibu menyusui adalah dengan berperan sebagai breastfeeding father. Breastfeeding father adalah dukungan seorang suami sebagai ayah kepada istrinya agar dapat berhasil dalam proses menyusui (Notoadmodjo, 2012).
Hasil penelitian menjelaskan dengan adanya dukungan dari suami, maka emosional ibu akan stabil dan termotivasi untuk memberikan bayinya dengan gizi yang baik yaitu ASI eksklusif, dibuktikan dengan sangat sedikit bayi yang diberikan makanan tambahan setelah diberikan edukasi kepada para suami untuk memberikan dukungan kepada istri untuk memberikan ASI secara eksklusif (Matare et al., 2019).

Hasil penelitian sejalan dengan teori tentang dukungan suami dalam pemberian ASI eksklusif. Sebagian besar suami di Desa Pelamunan Wilayah Kerja UPT Puskesmas Kramatwatu mendukung istrinya dalam memberikan ASI Eksklusif sehingga ibu mendapatkan dukungan secara emosional dan bantuan-bantuan praktis dalam pemberian ASI eksklusif.

\section{Gambaran Pemberian ASI Eksklusif berdasarkan Tingkat Pengetahuan Ibu tentang ASI eksklusif Di Desa Pelamunan Wilayah Kerja UPT Puskesmas Kramatwatu Kabupaten Serang Provinsi Banten Tahun 2019}

Tabel 6. Distribusi Frekuensi Pemberian ASI Eksklusif berdasarkan Tingkat Pengetahuan Ibu tentang ASI Eksklusif Di Desa Pelamunan Wilayah Kerja UPT Puskesmas Kramatwatu Kabupaten Serang Provinsi Banten Tahun 2019

\begin{tabular}{|c|c|c|c|c|c|c|}
\hline \multirow{3}{*}{$\begin{array}{c}\text { Tingkat } \\
\text { Pengetahuan }\end{array}$} & \multicolumn{4}{|c|}{$\begin{array}{c}\text { Pemberian ASI } \\
\text { Eksklusif }\end{array}$} & \multirow{3}{*}{ n } & \multirow{3}{*}{$\%$} \\
\hline & \multicolumn{2}{|c|}{$\mathbf{Y a}$} & \multicolumn{2}{|c|}{ Tidak } & & \\
\hline & $\mathbf{F}$ & $\%$ & $\mathbf{F}$ & $\%$ & & \\
\hline Kurang & 2 & 67 & 1 & 33 & 3 & 100 \\
\hline Baik & 40 & 79 & 11 & 21 & 51 & 100 \\
\hline Jumlah & 42 & & 12 & & 54 & \\
\hline
\end{tabular}

Sumber: Data Primer Periode April 2019

Tabel 6 diperoleh hasil bahwa dari 54 responden, mayoritas ibu yang memberikan ASI Eksklusif adalah ibu yang memiliki pengetahuan baik tentang ASI Eksklusif yaitu dengan jumlah 40 orang (79\%). Pengetahuan merupakan pengindraan manusia, atau hasil tahu seseorang terhadap objek melalui indra yang dimilikinya. Sebagian besar pengetahuan diperoleh melalui indra pendengaran yaitu telinga dan indra penglihatan yaitu mata. Pengetahuan juga dapat diukur dengan cara orang bersangkutan mengungkapkan hal-hal yang diketahuinya dalam bentuk bukti jawaban, baik lisan maupun tulisan (Notoadmodjo, 2010). Pengetahuan ibu yang kurang tentang ASI 
Faletehan Health Journal, 8 (1) (2021) 58-64

Eksklusif akan menyebabkan gagalnya pemberian ASI Eksklusif karena ibu tidak mempunyai motivasi untuk memberikan ASI Eksklusif kepada bayinya dan sebaliknya pengetahuan ibu yang baik akan menyebabkan keberhasilan dalam pemberian ASI eksklusif sehingga ibu termotivasi untuk memberikan ASI Eksklusif kepada bayinya (Astuti, 2013).

Kurangnya pengetahuan tentang ASI Eksklusif juga dibuktikan dengan adanya hasil penelitian kualitatif di negara berkembang dilakukan dengan wawancara mendalam untuk mengidentifikasi bahwa kurangnya pengetahuan menjadi penghambat utama pemberian ASI eksklusif. Salah satu hasil wawancaranya adalah "... saya berencana untuk menyusui bayi saya dengan ASI selama enam bulan tetapi saya tidak tahu berapa kali frekuensi menyusui yang seharunya dalam sehari." (Zohoori et al., 1993). Hal ini sejalan antara teori, dalam hasil penelitian yang didapatkan sebagian besar ibu di Desa Pelamunan Wilayah Kerja UPT Puskesmas Kramatwatu mempunyai pengetahuan yang baik sehingga termotivasi memberikan ASI Eksklusif kepada bayinya.

\section{Simpulan}

Setelah penelitian ini dilakukan maka dapat disimpulkan:

1. Gambaran usia ibu di Desa Pelamunan Wilayah Kerja UPT Puskesmas Kramatwatu Kabupaten Serang Provinsi Banten Periode Bulan April Tahun 2019 diperoleh sebagian besar memiliki usia yang tidak berisiko (20-35 tahun) yaitu sebanyak 37 orang (84\%).

2. Gambaran paritas ibu di Desa Pelamunan Wilayah Kerja UPT Puskesmas Kramatwatu Kabupaten Serang Provinsi Banten Periode Bulan April Tahun 2019 ibu yang memiliki usia 0-6 bulan sebagian besar paritas ibu adalah multipara atau grande multipara yaitu sebanyak 31 orang $(77,5 \%)$.

3. Gambaran pendidikan ibu di Desa Pelamunan Wilayah Kerja UPT Puskesmas Kramatwatu Kabupaten Serang Provinsi Banten Periode Bulan April Tahun 2019 sebagian besar ibu berpendidikan rendah yaitu sebanyak 19 orang $(83 \%)$.

4. Gambaran pekerjaan ibu di Desa Pelamunan Wilayah Kerja UPT Puskesmas Kramatwatu Kabupaten Serang Provinsi Banten Periode
Bulan AprilTahun 2019 mayoritas ibu adalah yang tidak bekerja sebanyak 34 orang (77\%).

5. Gambaran dukungan suami di Desa Pelamunan Wilayah Kerja UPT Puskesmas Kramatwatu Kabupaten Serang Provinsi Banten Periode Bulan April Tahun 2019 sebagian besar suaminya sangat mendukung dalam pemberian ASI eksklusif sebanyak 35 orang $(81 \%)$.

6. Gambaran pengetahuan ibu tentang ASI Eksklusif di Desa Pelamunan Wilayah Kerja UPT Puskesmas Kramatwatu Kabupaten Serang Provinsi Banten Periode Bulan April Tahun 2019 mayoritas ibu memiliki pengetahuan yang baik tentang ASI Eksklusif yaitu sebanyak 40 orang (79\%).

\section{Saran}

Peran petugas kesehatan terhadap persiapan ibu untuk menyusui diharapkan dapat menyentuh semua kalangan dan diharapkan dapat memanfaatkan kemajuan teknologi yang ada seperti penyuluhan dengan menggunakan sosial media. Bagi peneliti diharapkan dapat melakukan penelitian dengan metode yang lebih baik dari penelitian deskriptif supaya dapat mengatasi dengan pasti apa hambatan proses menyusui yang terjadi di masyarakat.

\section{Referensi}

Afriyani, R., Savitri, I., \& Sa'adah, N. (2018). Pengaruh Pemberian ASI Eksklusif di BPM Maimunah Palembang. Jurnal Kesehatan, 9(2), 331. https://doi.org/10.26630/jk.v9i2.640

Asare, B. Y. A., Preko, J. V., Baafi, D., \& Dwumfour-Asare, B. (2018). Breastfeeding practices and determinants of exclusive breastfeeding in a cross-sectional study at a child welfare clinic in Tema Manhean, Ghana. International Breastfeeding Journal, 13(1), 19. https://doi.org/10.1186/s13006-018-0156-y

Asemahagn, M. A. (2016). Determinants of exclusive breastfeeding practices among mothers in azezo district, northwest Ethiopia. International Breastfeeding Journal, 11(1), 17. https://doi.org/10.1186/s13006-016-0081-x Astuti, I. (2013). Determinan Pemberian ASI Eksklusif Pada Ibu Menyusui. Health Quality, $4,1-76$.

Cai, X., Wardlaw, T., \& Brown, D. W. (2012). Global trends in exclusive breastfeeding. 
International Breastfeeding Journal, 7, 2-6. https://doi.org/10.1186/1746-4358-7-12

Dinkes Provinsi Banten. (2018). Profil Kesehatan Provinsi Banten 2017.

Febriyanti, Rosalina \& Ernawati, D. (2017). Analisis Faktor-faktor yang Mempengaruhi Pemberian ASI Eksklusif Di Desa Gilang Taman Sidoarjo. Journal of Chemical Information and Modeling, 53(9), 1689-1699.

Gobel, H. Van, Arsin, A. A., \& Gorontalo, P. K. (2012). Kabupaten Gorontalo Determinant Of Exclusive Breastfeeding In The Working Area Of Mongolato Health Centre Sub District Telaga Of Gorontalo District Universitas Hasanuddin , 2 . Bagian Biostatistik Fakultas kesehatan Masyarakat Universitas Alamat Korespond. 36.

Hargi, J. P. (2013). Hubungan dukungan suami dengan sikap ibu dalam pemberian asi eksklusif di wilayah kerja puskesmas arjasa kabupaten jember. Jember. http://repository.unej.ac.id/bitstream/handle/1 23456789/8412/Jayanta Permana Hargi 072310101008_1.pdf?sequence $=1$

Kemenkes. (2018). info DATIN (Pusat Data dan Informasi Kementrian RI). Kementerian Kesehatan RI, 1-7.

Kemenkes RI. (2004). Kepmenkes No. 450 Th. 2004 Tentang Pemberian ASI.pdf (pp. 1-3). https://aimi-

asi.org/storage/app/media/pustaka/Dasar-

Dasar Hukum/Kepmenkes No. 450 Th. 2004 Tentang Pemberian ASI.pdf

Kemenkes RI Badan Penelitian dan Pengembangan. (2018). Hasil Utama Riset Kesehatan Dasar. Kementrian Kesehatan Republik Indonesia, 1-100. http://www.depkes.go.id/resources/download /info-terkini/hasil-riskesdas-2018.pdf

Khoiriah, A. \& L. (2018). Faktor-Faktor yang Berpengaruh Terhadap Pemberian ASI Eksklusif pada Bayi Berumur di Bawah 6 Bulan di BPM Rusmiati Okta Palembang. Jurnal `Aisyiyah Medika, 2, 69-87.

Manuaba, I. A. C. (2013). Ilmu Kebidanan, Penyakit Kandungan, dan KB Untuk Pendidikan Bidan Edisi 2. Jakarta : EGC.

Matare, C. R., Craig, H. C., Martin, S. L., Kayanda, R. A., Chapleau, G. M., Kerr, R. B., Dearden, K. A., Nnally, L. P., \& Dickin, K. L. (2019). Barriers and Opportunities for Improved Exclusive Breast-Feeding Practices in
Tanzania: Household Trials With Mothers and Fathers. Food and Nutrition Bulletin, 40(3), 308-325.

https://doi.org/10.1177/0379572119841961

Notoadmodjo. (2010). Pengetahuan. Jakarta : Rineka Cipta.

Notoadmodjo. (2012). Promosi Kesehatan dan Prilaku Kesehatan. Jakarta : Rineka Cipta.

Nugroho, T. (2011). ASI dan Tumor Payudara Dilengkapi Kolostrum dan Gizi Seimbang Ibu Menyusui (Cet. 1). Nuha Medika.

Puspitasari, R. I. (2012). Gambaran Faktor-Faktor Yang Mempengaruhi Pemberian Susu Formula Pada Ibu Yang Mempunyai Bayi Usia 0 - 6 Bulan Di Bidan Praktek Swasta $\mathrm{Hj}$. Renik Suprapti Kelurahan Bantarsoka Kecamatan Purwokerto Barat Kabupaten Banyumas Tahun 2011. Jurnal Ilmiah Kebidanan, 2(1), 21-34.

UPT Puskesmas Kramatwatu. (2018). Laporan UPT Puskesmas Kramatwatu.

WHO. (2015). World Health Statistics 2015. In World Health Organization (Issue 1993).

Widdefrita, \& Mohanis. (2014). Peran Petugas Kesehatan Dan Status Pekerjaan Ibu Dengan Pemberian Asi Ekslusif. JKMA: (Jurnal Kesehatan Masyarakat Andalas), 8(1), 40-45.

Yusrina, A., \& Devy, S. R. (2017). Faktor Yang Mempengaruhi Niat Ibu Memberikan Asi Eksklusif Di Kelurahan Magersari, Sidoarjo. Jurnal PROMKES, 4(1), 11. https://doi.org/10.20473/jpk.v4.i1.2016.11-21

Zohoori, N., Popkin, B. M., \& Fernandez, M. E. (1993). Breast-feeding patterns in the philippines: A prospective analysis. Journal of Biosocial Science, 25(1), 127-138. https://doi.org/10.1017/S002193200002037X 